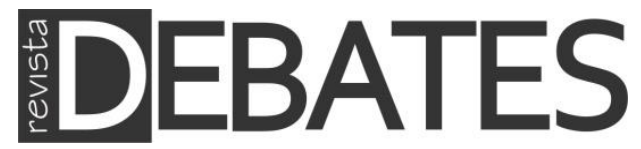

\title{
Capital social, pobreza e exclusão social na Itália
}

\author{
Social Capital, Poverty and Social Exclusion in Italy
}

\author{
Luca Andriani \\ Dimitrios Karyampas
}

\section{Resumo}

$\mathrm{O}$ artigo investiga a relação entre capital social e o padrão de vida das famílias italianas, baseando-se na pobreza e na exclusão social. A análise é desenvolvida em um nível regional, através de corte transversal dos anos de 2002 e 2003. Os índices de capital social que utilizamos são de atividade associativa no modelo de Putnam e um novo indicador baseado na densidade regional de distritos industriais. Ao usar o modelo empírico utilizado por Grootaert (2001), descobrimos que nossos resultados confirmam a teoria do mecanismo avançado de transição do capital social e pobreza de Narayan e Woolcock (2000). Além disso, encontramos correlaçôes significativa e negativa entre capital social e as medidas de exclusão social. Todos esses resultados levaram o artigo à conclusão de que o capital social é, positivamente, correlacionado a níveis altos de padrão de vida.

\section{Palavras-chave}

Capital Social; Distritos Industriais; Incidência da Pobreza; Hiato de Pobreza; Exclusão Social; Corte Transversal.

\section{Abstract}

The paper investigates the relationship between social capital and the standard living of the Italian households based on poverty and social exclusion. The analysis is developed at the regional level through cross-sections based in the year 2002 and in the year 2003. The indices of social capital that we use are the associational activity a la Putnam and a new proxy based on the regional density of industrial districts. By using the empirical model advanced by Grootaert (2001) we find that our results confirm the theory of social capital and poverty transition mechanism advanced by Narayan and Woolcock (2000). Moreover we find significant and negative correlation between social capital and the measures of social exclusion. All these results drive the paper to the conclusion that social capital is positively correlated to higher level of living standard.

\section{Keywords}

Social Capital; Industrial Districts; Poverty Incidence; Poverty Gap; Social Exclusion; Cross-Section. 


\section{Introdução ${ }^{1}$}

Desde as últimas duas décadas, governos de países em desenvolvimento têm aumentado a atenção em direção à pobreza e a exclusão social. Nos países europeus, em particular, essa preocupação foi ratificada no Tratado de Amsterdam e, mais recentemente, no Tratado de Lisboa, de acordo com o qual os governos europeus considerarão a redução da pobreza e da exclusão social como dois grandes alvoschave nas suas agendas políticas. Dentre os resultados dessa crescente atenção, em 2002 o Departamento de Estatística Italiano (ISTAT - Italian National Statistic Bureau), completou o primeiro relatório sobre pobreza e exclusão social nas regiōes italianas. Isso forneceu, pela primeira vez na história do país, uma imagem geral do empobrecimento socioeconômico em nível regional. Ao se aproveitar dessa documentação, o objetivo do artigo é investigar se o capital social reduz a pobreza e a exclusão social. Com esse propósito, definimos o capital social como o capital de conexôes gerado por ligações e a constante interação social entre indivíduos que compartilham normas, atitudes de confiança mútua, pertencimento comunitário, solidariedade e reciprocidade. As medidas de capital social que usaremos são, uma vez mais, DIND e o instrumento de Putnam. Ao usar o modelo empírico conduzido por Grootaert (2001), descobrimos que nossos resultados confirmam a teoria do mecanismo de transição do capital social e pobreza conduzida por Narayan e Woolcock (2000). Além disso, encontramos correlaçóes significativa e negativa entre capital social e as medidas da exclusão social. Todos esses resultados levaram o artigo à conclusão de que capital social é positivamente correlacionado a níveis altos de padráo de vida.

Trabalhos anteriores sobre o capital social na Itália têm associado esse conceito com desempenho econômico em níveis local e nacional. No produtivo trabalho de Putnam et al. (1993), o capital social tem sido associado com as diferenças em termos de bem-estar entre as regióes italianas. Essas diferenças têm sido expressas, principalmente, na boa governança e no crescimento da renda. Sabatini (2005a; 2005b; 2006) e Pistaferri (1999) associam capital social e rede de trabalho informal com estabilidade de emprego, melhor acesso ao mercado de trabalho e menores ganhos na Itália. Guiso, Sapienza e Zingales (2004) mostram que um nível maior de capital social é positivamente associado com o desenvolvimento financeiro na Itália. No entanto, para o nosso conhecimento, ainda falta uma ligação entre esse

\footnotetext{
${ }^{1}$ Agradecemos a John Driffill, Ron Smith, Klaus Nielsen, Asimina Christoforou, ao Departamento de Economia da Universidade de Economia e Negócios de Atenas pelo suporte técnico e aos participantes do seminário na Universidade de Creta. O suporte financeiro do Conselho de pesquisa Econômica e Social (concessão PTA-031-2006-00459) é extremamente apreciado.
} 
conceito e uma visão mais ampla do padrão de vida das famílias em países em desenvolvimento. A principal novidade do artigo é que, ao combinar capital social com pobreza e exclusão social, ambiciona ir além desses únicos aspectos da vida econômica. Em outras palavras, a análise irá capturar a relação entre capital social e a esfera multidimensional do padrão de vida em toda a região. Ao fazer isso, o primeiro problema que enfrentamos é separar operacionalmente o conceito de pobreza do conceito de exclusão social. $\mathrm{O}$ conceito de exclusão social foi reconhecido na literatura por ser complexo e rico de dimensões (TOWNSEND, 1979; NEGRI, 1995; BOHNKE, 2001; CAPACCI e CASTAGNARO, 2003; BURCHARDT, LE GRAND e PIACHAUD 1999). No entanto, se pobreza e exclusão social têm que ser um fenômeno singular ou dois aspectos distintos de uma sociedade, ainda é uma questão aberta sem solução (STRANGES, 2007). Este artigo está longe de resolver esse dilema e não tem essa intenção. Ao respeitar completamente as diferentes posiçóes assumidas pelos estudiosos, consideraremos esses dois aspectos como determinantes para uma melhor condição de vida. Em termos de metodologia e medidas, distinguiremos os dois conceitos com certo "grau de liberdade". Enquanto as definições de pobreza são essencialmente baseadas em valores monetários, seja em termos de consumo ou em termos de renda (GROOTAERT, 2001; GERTLER, LEVINE e MORETTI, 2006), exclusão social combina aspectos econômicos, sociais e humanos. Em outras palavras, esse conceito não é limitado apenas à esfera individual mais à sociedade (STRANGES, 2007; SEN, 1997). Portanto, consideramos pobreza e exclusão social como um processo contínuo da mesma "degradação" socioeconômica.

Trabalhos anteriores têm associado capital social com redução de pobreza, especialmente em relação às economias em desenvolvimento (GERTLER, LEVINE e MORETTI, 2003; 2006, GROOTAERT, 2001; VAN BASTELAER, 2000; e muitos outros). Woolcok (1998; 2001) e Narayan e Woolcok (2000) teoricamente mostram que a combinaçáo de laços horizontais fracos e fortes entre indivíduos e grupos representa um dos fatores chave para a redução da pobreza. Uma de suas contribuiçóes para a literatura é baseada na teoria do capital social e no mecanismo de transição da pobreza. De acordo com essa teoria, laços como ligação parental e familiar são prováveis de não serem suficientes para um escape individual da condição de pobreza. Isso se dá, principalmente, devido à limitação de recursos de um grupo fechado e de um sistema de dependência mutual e obrigaçôes entre seus membros, que não dão suficientes "movimentos de liberdade" para nenhum deles a fim de alcançar recursos externos ao grupo. Esse cenário negativo é chamado de armadilha de aproximaçáa por Narayana e Woolcock (2000). Um sistema 
diversificado de conexôes pode evitar esses problemas, já que podem representar uma espécie de portfólio de dotação social diversificada que pode reduzir o risco de cair na armadilha.

Positivamente inspirado pela literatura mencionada acima, nós desenvolvemos a análise empírica através de duas seções. Primeiramente, ao usar o modelo empírico conduzido por Grootaert (2001), investigamos o relacionamento entre capital social e as diferentes medidas de pobreza na Itália. A evidência empírica confirma a teoria do capital social e do mecanismo de transição da pobreza. Em segundo lugar, ao usar os índices de exclusão social ISE por Stranges (2007) e por Capacci e Castagnaro (2003), analisamos a associação entre capital social e exclusão social. Descobrimos que capital social afeta negativamente ambos os índices. Mais precisamente, a medida do capital social baseada em distritos industriais é significantemente relativa para o ISE de Stranges, enquanto a atividade associativa no modelo de Putnam é significantemente relativa às medidas de Capacci e Castagnaro.

A análise é desenvolvida por meio da seguinte estrutura.

Primeiro, apresenta-se um conhecimento teórico sobre o capital social e o mecanismo de transição da pobreza. Após, descreve-se as variáveis do capital social e as diferentes medidas de pobreza que consideramos na nossa análise. A seguir apresenta-se o modelo empírico associando capital social e pobreza, baseado no modelo usado por Grootaert (2001) e discute os resultados. A seção seguinte desenvolve uma análise teórica e empírica ligando o capital social e a exclusão social. Essa seção descreve as varáveis ISE adotadas, define o modelo empírico e discute os resultados. Por fim, apresentam-se as conclusões.

\section{Capital social e o mecanismo de transição da pobreza}

Nos últimos 20 anos, houve uma ampla evidência na literatura das ciências sociais que o capital social desempenha um papel importante na análise das atividades econômicas e no bem-estar humano. Em outras palavras, o capital social tem sido usado não apenas em modelos tradicionais de crescimento, mas também como uma variável capaz de capturar diferenças na qualidade de vida, exclusão social e pobreza entre países ou comunidades locais.

A ideia convencional em relação ao capital social pode ser resumida pelo aforismo comum "não é o que você sabe, mas quem você conhece." Não é incomum que durante tempos difíceis são nossa família e amigos que representam a "rede de confiança" final. Portanto, em um nível micro, podemos dizer que a ideia básica de "capital social" é que, a família, amigos ou associados de alguém constitui um trunfo 
importante, seja durante uma crise ou, menos instrumental, para o seu próprio bem (Woolcock em "Social Capital and Poverty Reduction", p. 22). Como um primeiro resultado, a rede construída através dessas interações tem benefícios mensuráveis para os membros dessas comunidades levando direta ou indiretamente para um nível mais alto de bem-estar (GROOTAERT, 2001). Em um nível macro, o capital social pode ser considerado um bem social derivado de um sistema baseado em confiança, valores e normas em comum. Knack e Keefer (1997) descobriram evidência empírica de uma forte relação entre confiança e rendas maiores e mais igualitárias, considerando 29 países. Eles têm argumentado que "sociedades caracterizadas por altos níveis de confiança entre indivíduos (confiança generalizada) são menos dependentes de instituiçôes formais para impor acordo" (p. 1253) e empresários são suscetíveis em devotar menos recursos ao monitorar prevaricação de parceiros, empregados e fornecedores e devotar mais tempo investigando produtos inovadores e processos. Por outro lado, maior confiança entre a comunidade e as instituições estabelece que a comunidade (confiança institucional) pode implicar consequências econômicas importantes. Oficiais do governo e políticas são percebidas como mais confiáveis e críveis. Ao compartilhar valores e normas, a literatura remete a convicçóes comuns e crenças e seus efeitos no funcionamento da sociedade como um todo (FUKUYAMA, 1995). Esse sistema de crenças comuns pode facilitar a cooperação e intensificar um senso de compromisso, ambos úteis para açôes coletivas.

Ainda assim, de acordo com Grootaert (2001), o benefício resultante desse sistema de conexôes e senso de comunidade é resultado de três mecanismos principais.

Primeiramente, o compartilhamento de informação entre membros de associações é suscetível de facilitar a difusão de inovaçôes. Nesse senso, as repercussões em nível local podem desempenhar um papel crucial no desempenho tecnológico das regióes (para uma análise mais exata, veja Saxenian, 1996). Além disso, maior atividade associativa pode reduzir informaçóes imperfeitas e, por tanto, menor custo de transação tanto no trabalho quando no mercado de crédito. $\mathrm{O}$ capital social poderia facilitar um melhor fluxo de informações entre mutuário e credor no mercado de crédito, assim como entre mandante e mandatário no mercado de trabalho.

Em segundo lugar, solidariedade e reciprocidade podem reduzir comportamentos oportunistas. Ostrom (2010) argumenta que ações cooperativas em comunidades locais desempenham um papel importante em administrar os 
recursos de "propriedade comum" e em evitar, ou pelo menos reduzir, exploração excessiva.

Em terceiro, atitudes compartilhadas e senso de pertencimento de comunidade podem facilitar a tomada de decisão coletiva. Putnam et al. (1993) mostrou que em regióes do norte da Itália um nível de associações sociais mais intensivas e um elevado grau de engajamento cívico, comparado com as regiôes do sul, promovem normas coletivas e confianças que são centrais na produção e manutenção do bem-estar da sociedade em temos de crescimento econômico e boa governança. Esses dois níveis duplos de capital social têm se integrado.

Considerando o conceito de pobreza como "uma privação pronunciada de bem-estar" (BANCO MUNDIAL, 2005, p. 9), o capital social como um recurso pode ser utilizado para reduzir essa privação.

A hipótese que o capital social possa afetar positivamente a pobreza tem sido confirmada empiricamente no desenvolvimento da literatura ao se utilizar diferentes metodologias e perspectivas.

Ferroni, Mateo e Payne (2008) mostram que o capital social, através da coesão social, afeta positivamente o crescimento econômico, a capacidade de investimento e a inovação dos países da América Latina. A coesão social, nesse sentido, é tratada como um recurso e o índice composto construído por eles se refere a uma combinação das dimensôes de capital social, como uma confiança interpessoal e institucional e a distribuição de oportunidades em termos de educação, renda e outras variáveis socioeconômicas. Eles descobriram que capital social é positivamente relacionado não apenas ao crescimento econômico, capacidade de inovação, mas também a qualidade da política de desenvolvimento e da estabilidade política.

Grootaert (2001) analisa a ligação entre capital social, bem-estar familiar e pobreza na Indonésia. A evidência empírica mostra que as famílias com maior capital social têm despesas maiores per capita, mais recursos e melhor acesso a crédito e são menos suscetíveis que seus filhos não frequentem a escola. Além disso, ao usar um modelo probito, Grootaert descobre que, a família mediana, com alta atividade associativa (medida de filiação), tem menor probabilidade de ser pobre do que as famílias com nenhuma filiação.

Oxendine (2007), ao usar uma pesquisa de dados envolvendo 29 estados nos Estados Unidos, descobriu uma relação negativa e significante entre desigualdade econômica e capital social. 
Narayan e Prichett (1997) demonstraram que capital social em um nível familiar tem um efeito positivo no bem-estar familiar na Tanzânia. Além disso, eles mostram que esse efeito funciona primariamente no nível de aldeia.

Isham (2000) mostra que capital social favorece a adoção da tecnologia (aumentando a adoção de fertilizante melhorado) devido ao fato que os fazendeiros nas aldeias com maior nível de capital social têm mais informação cumulativa.

Vamos usar o diagrama, apresentando por Woolcock e Narayan (2000), com o objetivo de descrever a dinâmica entre capital social e transição da pobreza.

De acordo com as definiçôes de capital social, dois elementos são cruciais para esse recurso funcionar. O primeiro é a importância da rede de contatos (conexôes e constante interação social entre indivíduos); o segundo é a importância de recursos incorporados (ex.: o fluxo de informações e a atitude em relação à cooperação). Esses dois elementos podem ser combinados através de um sistema de lações fortes e fracos (GRANOVOTTER, 1973; 1995) ou, em outras palavras, através de um balanço entre conexôes de "encapsulamento" (bonding) e de "ponte" (bridging). Simplificando, o desenvolvimento ocorre através de um mecanismo onde o capital social de encapsulamento (cooperação mútua e interação entre indivíduos pertencentes a uma mesma comunidade ou a um mesmo grupo: família, empresa...) e capital social de ponte (cooperação mútua e interação entre indivíduos pertencentes a diferentes comunidades ou grupos: áreas de atuação, grupos de trabalho de diferentes empresas...) coexistem. Se no primeiro cenário os indivíduos adquirem habilidades e recursos incorporados em sua comunidade inicial, na última eles adquirem "as habilidades e recursos para participar de redes de contatos que transcendam sua comunidade, assim juntando progressivamente o mainstream econômico" (WOOLCOCK e NARAYAN, 2000, p. 232).

A Figura 1 mostra a dinâmica entre o capital social e as transiçóes de pobreza.

(A) Indivíduos pobres de aldeias (mulheres, por exemplo) sem garantia de material recebem empréstimos ou ajuda graças a sua filiação em um pequeno grupo de pares. Isso os ajuda a iniciar ou expandir um pequeno negócio e, além disso, melhorar o bem-estar de suas famílias.

(B) Por causa da extensão limitada e de recursos (materiais e não materiais) de qualquer grupo, o retorno alcançara um máximo, após o qual começará a diminuir.

(C) Isso ocorre, especialmente, quando o grupo depende exclusivamente de doações provenientes do capital social de encapsulamento. 
(D) Além disso, membros de longa duração do grupo podem descobrir (especialmente no caso de programas de créditos baseados em grupos) que obrigaçôes e comprometimentos com seus colegas representam sérios obstáculos para um maior avanço, especialmente para os mais ambiciosos.

(E) A fim de escapar dessa armadilha de aproximação, membros tentam construir uma rede de contatos mais diversificada, criando laços com membros pertencentes a outros grupos. Isso aumenta o nível do capital social de ponte e, além disso, as oportunidades econômicas sobem.

De acordo com a figura, enquanto grupos sociais pertencentes a aldeias pobres intensificam ligaçóes de encapsulamento a fim de lutar contra a incerteza (abordagem de "defesa"), grupos não pobres tendem a criar um sistema de rede de contatos de ponte e atuar "ofensivamente". Essa visão está alinhada com o conceito de "Força de posição da proposição" seguido por Lin (2001). Isso é um postulado indicando que quanto melhor é a posição de origem do membro, se torna mais suscetível que esse membro acessará e melhor utilizará o capital social. Em outras palavras, pessoas começando com uma maior doaçáo têm uma maior probabilidade de diversificar seu capital social entre os lados de encapsulamento e de ponte.

Como Woolcock e Narayan (2000) salientam, um dos principais desafios é identificar as condições sob as quais ajudar comunidades pobres a ter acesso a um estoque mais diverso de capital social de ponte sem subestimar, simultaneamente, os vários aspectos positivos do seu estoque de capital social de encapsulamento.

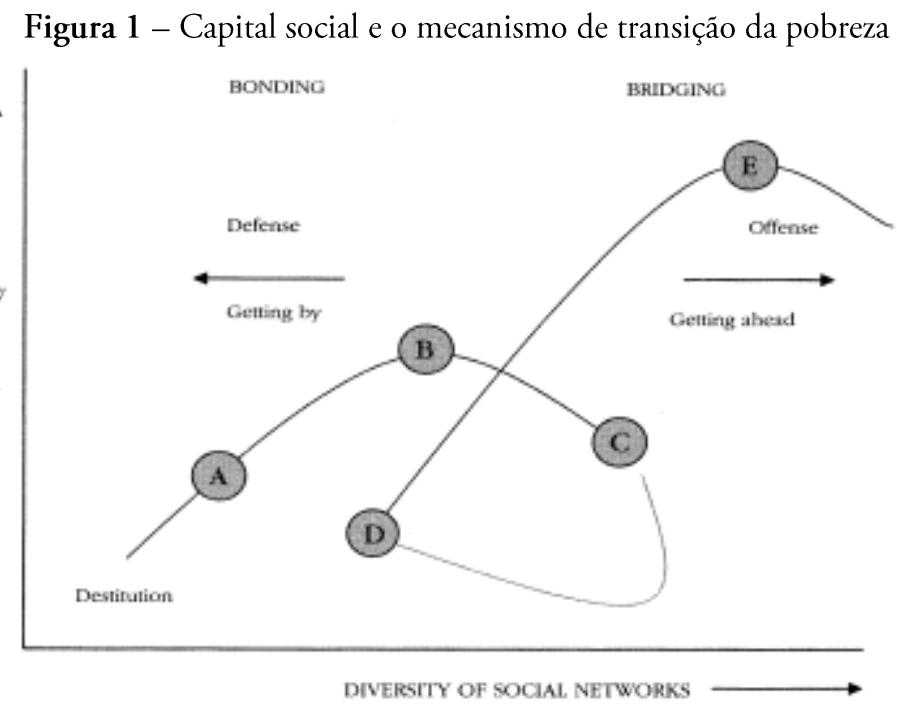

Fonte: Narayan e Woolcock (2000) 


\section{Medidas de Pobreza: Dados e metodologia}

O conjunto de dados utilizados para construir os indicadores de capital social é baseado no "80 Censo geral da Indústria e Distritos Industriais (2001)" (ISTAT, 2001) e o relatório "Organizações voluntárias na Itália" (ISTAT, 2001). Os indicadores de pobreza, o indicador de capital humano e as variáveis de características demográficas e geográficas derivam do "Censo geral da população e famílias (2001)" (ISTAT), a pesquisa de "Pobreza e Exclusão Social" refere-se ao período de 2002 (ISTAT, 2003) e os dados anuais regionais do "Sistema de indicador territorial", também do ISTAT. O propósito da pesquisa sobre pobreza e exclusão social é alcançar, pela primeira vez, informaçôes mais precisas sobre a condição de pobreza regional a fim de melhor direcionar políticas estruturais em nível local. Na pesquisa, a amostra é baseada em 27 mil famílias, mas os resultados foram ponderados em um nível regional médio, nos fornecendo observações de $n=$ 20. Finalmente, as variáveis financeiras são derivadas de relatórios de "economia regional" fornecidos anualmente pelo Banco da Itália.

Nas próximas subseções, introduziremos uma breve descrição das medidas de pobreza. Então, forneceremos uma análise descritiva geral.

\section{Medidas de Pobreza}

Nossa ambição aqui não é revisar toda a literatura sobre pobreza, mas descrever os índices que utilizamos e discutir alguns problemas de relevância para os nossos estudos. A literatura de estudos em desenvolvimento constrói as medidas de pobreza através de duas magnitudes principais: renda e consumo ${ }^{2}$. Independentemente da disputa na literatura, se o consumo é mais apropriado que a renda para melhor capturar as taxas de pobreza ou ao contrário, as medidas de pobreza do OECD, e, além disso, aquelas identificadas na pesquisa do ISTAT são baseadas, principalmente, na abordagem do consumo (gastos). Em países em desenvolvimento, uma das razões em favor desse indicador é relacionada à "hipótese de renda permanente" (figura 2).

\footnotetext{
${ }^{2}$ Essa ainda é uma discussão aberta e sem resolução entre estudantes e cientistas sociais sobre qual uma das duas variáveis é mais apropriada no objetivo de identificar o bem-estar de um individual ou família (veja Goodman et al. 1997; Atkinson, 1983; Banco Mundial, 2005; para uma análise completa dessa diatribe em particular).
} 
Figura 2 - "Ciclo de vida"

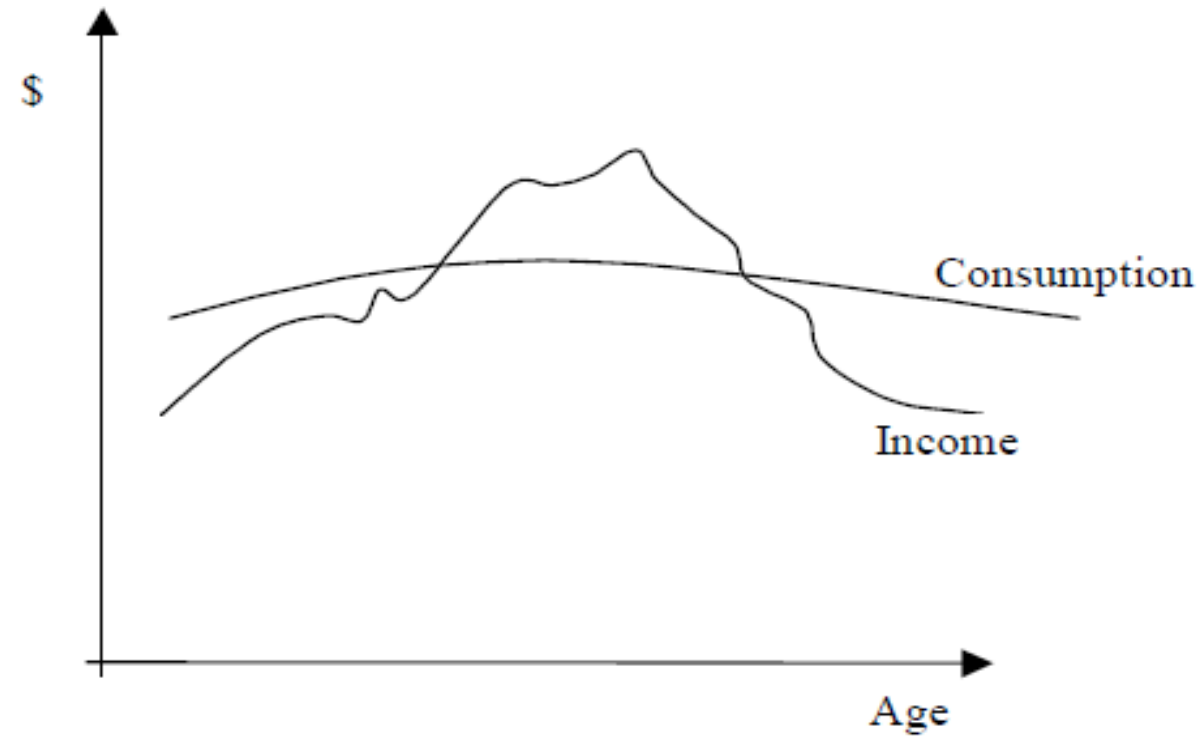

Fonte: "Introdução à análise de pobreza" World Bank Institute, 2005, p. 28.

A ideia básica por trás da hipótese de renda permanente é a seguinte: enquanto durante o ciclo de vida a renda de um indivíduo é suscetível a aumentar e cair ano a ano, o consumo permanece relativamente estável. Em outras palavras, enquanto a renda transitória é salva, a renda em longo prazo ("permanente") é amplamente consumida (BANCO MUNDIAL, 2005).

A fim de identificar as medidas quantitativas de pobreza, tivemos de estabelecer a chamada linha de pobreza, que é o nível de consumo que uma família precisa para escapar da pobreza. A linha de pobreza relativa $z$, feita pelo ISTAT (2003), se refere ao consumo per capita $c$, ajustada pela padronizaçáo do fator $\beta$, chamado de "escala de equivalência", utilizada para determinar a linha de pobreza quando o número dos membros familiares for diferente de "2" (veja o Apêndice para detalhes formais).

$$
z=\beta c
$$

Conforme o ISTAT (2003), a linha de pobreza relativa em 2002 para uma família de dois membros é $z=€ 823,45$, quando para uma família de quatro membros é de $\mathrm{z}=€ 1342,22$. Consequentemente, uma família de dois membros é 
considerada pobre se tem um gasto médio mensal de consumo menor ou igual à média nacional per capita $(€ 823,45)$.

Para os nossos propósitos, usaremos mais de uma medição quantitativa: Índice Headcount (ou incidência de pobreza), o Índice de Hiato de Pobreza (ou intensidade de pobreza), o índice de "certamente pobre" e o índice de "somente pobre" (para uma análise mais formal e descrição de cada índice, veja o apêndice). Os dois últimos índices são utilizados pela ISTAT com o objetivo de analisar a pobreza em diferentes níveis.

O Índice Headcount (HC) mede a proporção da população que é contada como pobre (BANCO MUNDIAL, 2005). Mais precisamente, ele mede a porcentagem das famílias as quais o consumo é abaixo da linha de pobreza relativa. O Índice de Hiato de Pobreza, ou poverty gap, (PG) indica a intensidade da pobreza. Simplificando, ele mede a porcentagem média de o quanto a média de gasto das famílias pobres está abaixo da linha de pobreza (ISTAT, 2003; BANCO MUNDIAL, 2005).

O índice de "surely poor" (SP) identifica o percentual de famílias nas quais os gastos são menores que $80 \%$ da linha padrão de pobreza $z$ (ISTAT, 2003).

$$
S P \rightarrow \mu<\alpha z
$$

Onde $\alpha=0.8$. Isso significa que o índice "surely poor" se refere a uma linha de pobreza $\mu$ a qual o valor é $80 \%$ da linha de pobreza relativa padrão.

O índice "just poor" (JP), identifica o percentual de famílias as quais os gastos são entre a linha de surely poor $\mu_{\mathrm{e}}$ a linha de pobreza relativa z (ISTAT, 2003).

$$
J P \rightarrow z \leq \gamma \leq \mu
$$

Observe que os índices Headcount e de Hiato de Pobreza são baseados no ano de 2003. Isso fornece para a análise a possibilidade de fazer comparaçôes entre esses índices quantitativos e as variáveis de exclusão social, calculadas por Stranges (2007) e Capacci e Castagnaro (2003), baseadas no ano de 2003. Diferente de HC e PG, os indicadores SP e JP são baseados no ano de 2002. De acordo com os nossos conhecimentos, o ISTAT não replicou essas medidas nos anos seguintes. 


\section{Análise descritiva}

De acordo com Felice (2005, p.1), "a Itália é provavelmente o país europeu com disparidades regionais mais amplas e historicamente arraigadas". Tal fato pode ser verdade não apenas em termos de desempenho econômico, mas também em termos de pobreza. A Tabela 2 mostra que a pobreza varia bastante nas regióes e isso ocorre para cada uma das diferentes dimensões de pobreza que consideramos. Em termos do Índice de Headcount, a Sicília, uma região sulina, é a região que apresenta a porcentagem mais elevada de famílias $(25,5 \%)$ nas quais o consumo per capita é abaixo da linha de pobreza relativa, enquanto Basilicata, também no sul, é a regiấo com a pontuação máxima em relação ao Hiato de Pobreza $(25,8)$. Isso significa as que famílias pobres em Basilicata gastam em média 25,8\% menos do que a família italiana média, cujos gastos recaem na linha de pobreza relativa $z$. Consequentemente, sem surpresas, Basilicata é também a região com o maior percentual de famílias "surely poor" $(15,5 \%)$, enquanto a Calábria é a região com o maior percentual de famílias "just poor" (15,5\%).

Tabela 1 - Estatísticas das medidas de pobreza

\begin{tabular}{c|c|c|c|c}
\hline & HC & PG & SP & JP \\
\hline Média & 12,13 & 20,51 & 6,22 & 6,79 \\
\hline Mediana & 8,55 & 20,55 & 4,1 & 4,8 \\
\hline Desvio Padrão & 7,94 & 3,01 & 4,91 & 4,14 \\
\hline Máxima & 25,50 & 25,80 & 15,50 & 15,10 \\
\hline Mínima & 4,00 & 14,90 & 1,50 & 2,20 \\
\hline Variaçáo & 21,50 & 10,90 & 14,00 & 12,90 \\
\hline N. Obs. & 20 & 20 & 20 & 20 \\
\hline
\end{tabular}

Fonte: Produzido pelo autor.

Se focarmos a atenção na incidência de pobreza $(\mathrm{HC})$, a faixa entre a região mais pobre e a menos pobre é bastante impressionante $(21,5 \%)$. Em particular Vêneto, uma região localizada no nordeste, têm apenas $4 \%$ das famílias que podem ser consideradas pobres, $21,5 \%$ menos que na Sicília. A média do índice HC é por volta de $12,13 \%$. Todas as regióes do sul apresentam valores acima da média. No entanto, se considerarmos o valor da média do hiato da pobreza, mais duas das regiōes do norte apresentam valores acima da média: Piemonte e Trentino-Alto Ádige. A última apresenta um valor de hiato de pobreza maior que o da Sicília. Em termos de distribuição geográfica da pobreza na Itália, a Tabela 2 e a Figura 3 descrevem uma imagem mais clara e geral. A Tabela 2 confirma que o maior percentual de famílias pobres está concentrado nas regióes do sul (para a divisão 
geográfica das regiões entre noroeste, nordeste, centro, sul e ilhas, veja o Apêndice). Mais precisamente, a Tabela 2 mostra que a proporção de famílias pobres sobre o total da população é maior no Sul e nas Ilhas $(20,7 \%$ e $22,7 \%$ contra 5-6\% no resto do país). Entretanto, o hiato de pobreza apresenta menor disparidade entre as partições geográficas. É interessante notar que nas regiōes do norte de Piemonte, Emília-Romanha, Trentino-Alto Ádige e Friul-Veneza Júlia, o valor de hiato da pobreza é acima de $20 \%$. Esses valores são maiores que em qualquer região pertencente ao centro da Itália e relativamente próximos à média do sul.

Tabela 2 - Distribuição geográfica da pobreza na Itália (2003): Incidência da pobreza e Hiato da pobreza

\begin{tabular}{c|c|c}
\hline Áreas & Índice Headcount & Índice de hiato de pobreza \\
\hline Noroeste & $5,4 \%$ & $18,7 \%$ \\
\hline Nordeste & $5,2 \%$ & $19,7 \%$ \\
\hline Centro & $5,7 \%$ & $18,2 \%$ \\
\hline Sul & $20,7 \%$ & $23,2 \%$ \\
\hline Ilhas & $22,5 \%$ & $22,1 \%$ \\
\hline Itália & $10,6 \%$ & $21,4 \%$ \\
\hline
\end{tabular}

Fonte: Dados do ISTAT (2003).

A Figura 3 indica a distribuição da pobreza ao levar em conta os diferentes níveis de pobreza medidos pelo ISTAT (2003). Enquanto a média das famílias realmente pobre na Itália é por volta de $5,1 \%$, no sul essa proporção mais que dobra. Podemos notar um cenário parecido para a proporção de famílias que foram rotuladas como "just poor". 
Figura 3 - Pobreza na Itália em 2002

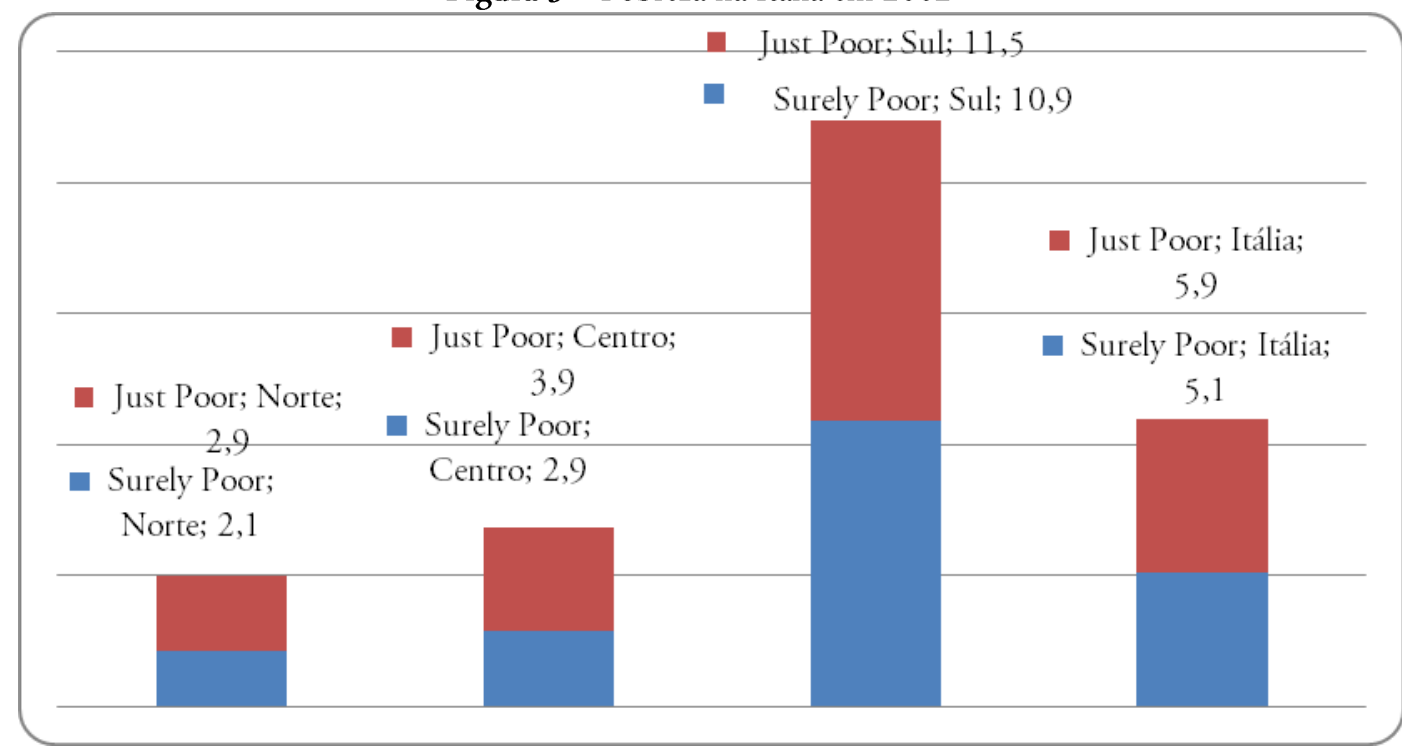

Fonte: Dados do ISTAT (2003).

A Tabela 3 mostra a matriz de correlação entre a pobreza e os indicadores de capital social.

Tabela 3 - Correlação capital social e pobreza

\begin{tabular}{c|c|c|c|c|c|c}
\hline & HC & PG & SP & JP & Dind & Associação \\
\hline HC & 1,00 & & & & & \\
\hline PG & 0,83 & 1,000 & & & & \\
\hline SP & 0,96 & 0,86 & 1,00 & & & \\
\hline JP & 0,96 & 0,818 & 0,962 & 1,00 & & \\
\hline Dind & $-0,55$ & $-0,50$ & $-0,55$ & $-0,54$ & 1,00 & \\
\hline Associaçáo & $-0,35$ & $-0,09$ & $-0,29$ & $-0,33$ & 0,07 & 1,00 \\
\hline
\end{tabular}

Fonte: Produzido pelo autor.

Ambos os indicadores, o instrumento Putnam e o dind, são correlacionados negativamente com os diferentes indicadores de pobreza. Nota-se que, mesmo que os indicadores SP e JP sejam defasados por um ano em comparaçáo com o $H C$ e $P G$, a correlação entre as primeiras medidas de pobreza e as últimas é muito alta. $\mathrm{O}$ coeficiente de correlação entre os diferentes indicadores de pobreza é entre 0.81 e 0.96. Isso pode sugerir certa persistência na tendência da pobreza em todas as regióes. 
Figura 4 - Capacci-Castagnaro ISE e dind

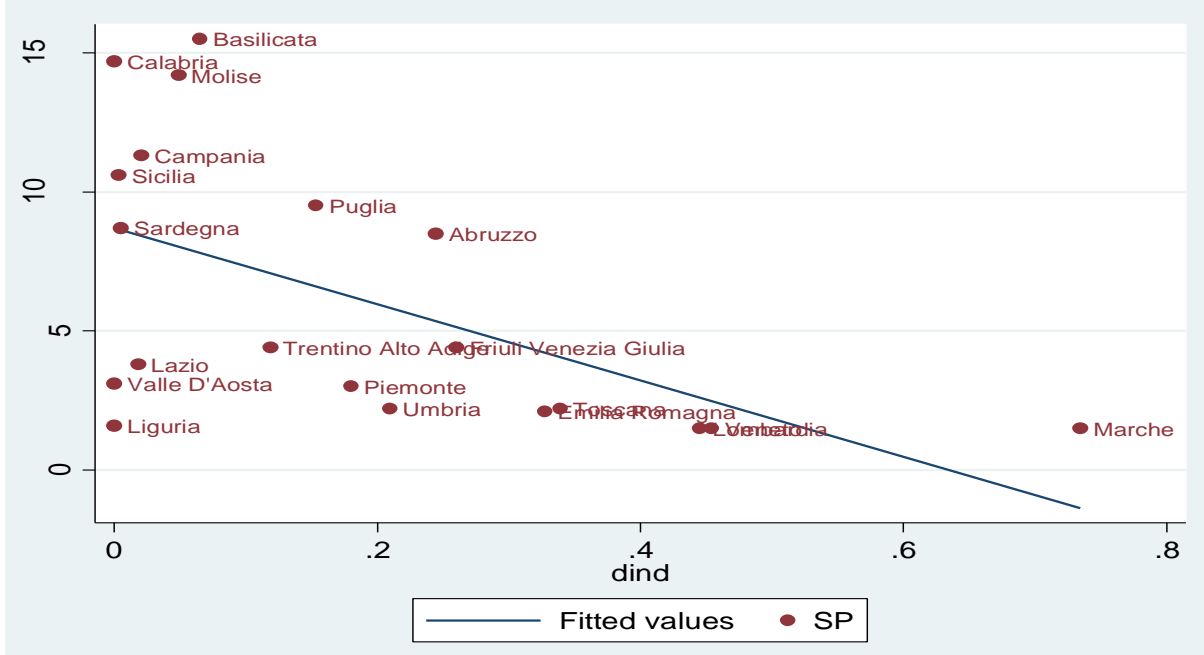

Fonte: Produzido pelo autor.

A Figura 4 considera o relacionamento entre a linha de pobreza relativa mais baixa (indicador SP) e o indicador de capital social (dind). Conforme o gráfico, todas as regiōes acima do nível de $10 \%$ da pobreza (Sicília, Campânia, Molise etc.) apresentam um nível muito baixo de capital social. Por outro lado, a regiáo com o maior nível de capital social (Marche) está longe de uma condição de pobreza dramática mesmo que essa região esteja localizada no norte do país.

\section{Capital social e pobreza: Análise Empirica}

Nesta seção, vamos apresentar nossos modelos empíricos a fim de capturar o relacionamento entre os indicadores de capital social e as medidas de pobreza mencionadas nas seções anteriores.

Devido ao baixo número de observações, e, portanto, ao escasso grau de liberdade, em nossos modelos empíricos escolhemos controlar as variáveis de acordo com uma seleção severa, levando em consideração razões metodológicas e teóricas.

$\mathrm{Na}$ verdade, a análise e os modelos empíricos que apresentamos são inspirados por diversos trabalhos, bastante populares nessa literatura em particular, como Narayan e Pritchett (1997), Helliwell (2002), Putnam et al. (1993), Putnam (2000) e Grootaert (2001). Mais especificamente, reproduziremos o modelo empírico proposto por Grootaert (2001) ao integrar duas modificaçóes importantes. Primeiramente, integramos a variável de capital social DIND com os indicadores de capital social. Em segundo lugar, um dos problemas apontados por Grootaert 
(2001) é a causalidade reversa que o seu modelo empírico pode ter. Um elemento de robustez do nosso modelo é baseado em diferentes variáveis defasadas do capital social em relação aos indicadores de pobreza. Enquanto o primeiro deriva de pesquisas referentes ao ano de 2001, o último se refere aos anos de 2002 (SP e JP) e 2003 (HC e PG). Variáveis regressoras do capital social defasadas por um ou dois anos podem reduzir dramaticamente a probabilidade de incorrer em problemas de causalidade reversa.

A equação (4) representa o conjunto de regressões sobre a pobreza objetiva.

$$
\text { Poverty }_{i}^{j}=\beta_{0}+\beta_{1} \text { sc }_{i}^{k}+\beta_{2} \text { education }_{i}+\beta_{3} \ln \text { asset }_{i}+\beta_{4} X_{i}+\beta_{5} Z_{i}+u_{i}
$$

\section{Onde}

Poverty $_{i}^{(j)}$ indica a $j$ th $(j=$ HC, PG, SP, JP) medida de pobreza objetiva apresentada na seção anterior para $i$ th regióes .

$s c$ indica a $k$ th $(k=$ dind, associação $)$ medida de capital social para $i$ th regiôes.

educação é a variável capital humano.

ln asset ${ }^{3}$ é a dotação domiciliar de outros recursos (no nosso caso, recursos financeiros)

$X$ é o vetor das características das famílias (tamanho das famílias)

$Z$ é o vetor das caracterísitcas da região

$u$ é o termo de erro.

Note que, como Grootaert (2001), não incluímos na regressão a renda per capita variável. Existe mais que uma razão para suportar essa escolha. Primeiro, os índices de pobreza que estamos usando são baseados em variáveis de consumo. Consumo e renda estão fortemente correlacionados no curto prazo. Em razão de a nossa análise ser baseada em corte-transversal isso pode causar problemas de endogeneidade. Em segundo lugar, como Stranges (2007) aponta, a medição quantitativa da pobreza regional na Itália é caracterizada por uma série de problemas. Um desses problemas é relacionado à alta diferenciação existente entre as

\footnotetext{
${ }^{3}$ Note que a variável $l n$ asset é calculada nos anos de 2001 e 2002, dependendo da regressão. Quando as variáveis dependentes são $S P$ e $J P$ o ln asset é baseado no ano de 2002, enquanto quando as variáveis dependentes são $H P$ e $P G$ o regressor é baseado no ano de 2001.
} 
regiôes, criando dificuldades severas ao compará-las utilizando um único limite, não ponderando a base do poder de compra real da área diferente. Por exemplo, Helliwell (2002) salienta as desvantagens em identificar ligação entre renda e bemestar. Para comparar renda entre países, Helliwell (2002) utiliza o PIB real per capital medido com paridades de poder de compra (PPC). O problema com o nosso conjunto de dados é que cada renda regional, mesmo pertencendo ao mesmo país, deve ser ajustada por diferentes "inflaçôes regionais", se não medidas com PPC. Em terceiro lugar, ainda segundo Helliwell (2002), a teoria e algumas pesquisas prévias sugerem que o efeito da renda pode ser não linear por natureza, com menores efeitos de bem-estar ligados a aumentos na renda além do nível definido pelas expectativas e hábitos de cada indivíduo ou sociedade. Devido a um baixo número de observações, evitamos utilizar modelos de estimativa não paramétricos.

As intuiçôes e as razões por trás da escolha das variáveis específicas utilizadas na equação (4) são as seguintes:

A variável educação e ln asset representam a dotação de capital por parte das famílias. Maiores níveis de educação, ou melhor, saúde financeira devem representar importantes instrumentos para uma família escapar da pobreza. A variável de "educação" vem do censo feito pelo ISTAT em 2001. Essa variável indica a proporção de indivíduos com um diploma. A variável log asset foi originada pelas pesquisas "regionais econômicas" que o Banco da Itália desenvolveu anualmente. Essa variável indica a quantidade de recurso financeiro per capita em nível regional. Mais precisamente, ela indica o investimento coletivo no mercado de açóes per capita. Na literatura econômica, não é impopular associar o nível de saúde financeira ao nível de bem-estar e crescimento econômico de uma sociedade. Embora na teoria de finanças e crescimento ainda exista uma disputa aberta sobre se as finanças causam crescimento ou o cenário reverso. No entanto, parece existir um grande consenso sobre a associação positiva entre as duas variáveis (DRIFFILL, 2003). O vetor $X$ das características familiares representa o perfil demográfico. Mais precisamente, a variável que consideramos no modelo é o tamanho da família. Famílias em condiçóes de pobreza atribuem uma maior proporção de seus orçamentos para comida e bens necessários. Estudos da curva de Engel e pobreza, com particular atenção em insegurança alimentar, (GABBERT e WEIKARD, 2005) mostram que o relacionamento entre a fatia do orçamento para a alimentação e o tamanho da família é positivo, quanto às parcelas de orçamento para a alimentação diminuem com a renda. Ou seja, conforme a renda diminuiu as famílias devotam menos valor da renda para os gastos com comida. Por outro lado, famílias maiores gastam uma quantia maior da renda com comida do que famílias menores. Isso 
indica que, em caso de condição de pobreza, o tamanho da família desempenha um papel crucial no mapeamento dos gastos em bens necessários. Famílias de tamanho maiores, por tanto, afetam negativamente o bem-estar de seus membros já que os recursos têm que ser compartilhados entre mais indivíduos. Isso, claro, ocorre particularmente quando uma família já pertence a um menor vínculo na linha da pobreza. O Vetor $Z$ representa o perfil geográfico. No nosso caso, a característica regional considerada é a densidade populacional. Uma proporção de estudos bastante consistente sobre pobreza e capital social (VAN BASTELAER, 2000; HIRSCHL e RANK, 1991; OXENDINE, 2007) tem mostrado que a densidade populacional desempenha um papel importante na distribuição de pobreza. Por exemplo, Van Bastelaer (2000) realça como nos mecanismos de microfinanciamento para os pobres no Arkansas as famílias encontram mais dificuldades na presença de um nível baixo de densidade populacional. Maior concentração e, por tanto, proximidade entre os membros facilitam o acesso dos pobres ao crédito local devido à realização de reunião ordinária, um conhecimento mútuo mais elevado de qualidade de crédito e acompanhamento. Hirschl e Rank (1991) encontraram resultados similares ao analisar programas de bem-estar social entre condados dos EUA. Eles descobriram que a densidade populacional afeta positivamente a participação dos residentes nesses programas de bem-estar. Novamente, uma das possíveis razões apontada por eles é baseada na hipótese que, distância física reduzida diminui a falta de informação e, consequentemente, os obstáculos para acessar aos programas, podem ser mais problemáticos onde os residentes estão mais dispersos. Podemos acrescentar uma razão extra. Uma densidade populacional elevada é suscetível a aumentar a interação social. Isso não se refere à interação de encapsulamento, mas a um nível maior de atividades associativas devido a maiores oportunidades de encontrar pessoas e manter reunióes mais regularmente. Isso pode aumentar a rede de contatos da família e as conexôes que os membros da família constroem fora de seus grupos de encapsulamento. 
Tabela 4 - Capital social e pobreza

\begin{tabular}{|c|c|c|c|c|}
\hline & $\begin{array}{c}\text { Eq.1 } \\
\text { HC }\end{array}$ & $\begin{array}{c}\text { Eq.2 } \\
\text { PG }\end{array}$ & $\begin{array}{c}\text { Eq.3 } \\
\text { SP }\end{array}$ & $\begin{array}{c}\text { Eq.4 } \\
\text { JP }\end{array}$ \\
\hline Dind & $\begin{array}{c}-15.244^{* * *} \\
(3,931) \\
\end{array}$ & $\begin{array}{c}-7,480^{* * *} \\
(1,949)\end{array}$ & $\begin{array}{c}-6.913^{* * *} \\
(2,069)\end{array}$ & $\begin{array}{c}-6.485^{\text {*** }} \\
(1,350) \\
\end{array}$ \\
\hline Associação & $\begin{array}{c}-5,780^{* *} \\
(2,190)\end{array}$ & $\begin{array}{l}-0,529 \\
(1,287)\end{array}$ & $\begin{array}{l}-1,275 \\
(0,877)\end{array}$ & $\begin{array}{l}-1,622 \\
(0,923)\end{array}$ \\
\hline Educação & $\begin{array}{l}-0,283 \\
(0,330)\end{array}$ & $\begin{array}{l}-0,072 \\
(0,145)\end{array}$ & $\begin{array}{c}0,119 \\
(0,218)\end{array}$ & $\begin{array}{l}-0,022 \\
(0,195)\end{array}$ \\
\hline Lnasset & $\begin{array}{l}-1,991 \\
(2,648) \\
\end{array}$ & $\begin{array}{c}1,299 \\
(0,801) \\
\end{array}$ & - & - \\
\hline Tamanho03 & $\begin{array}{l}14,740^{*} \\
(7,745)\end{array}$ & $\begin{array}{c}12.224^{* * *} \\
(3,202)\end{array}$ & - & - \\
\hline Densidade03 & $\begin{array}{l}-0,009 \\
(0,011)\end{array}$ & $\begin{array}{c}-0,011^{\text {** }} \\
(0,004)\end{array}$ & - & - \\
\hline Lnasset 02 & - & - & $\begin{array}{c}-2,644^{* * *} \\
(0,634)\end{array}$ & $\begin{array}{c}-1.624^{* * *} \\
(0,458)\end{array}$ \\
\hline Tamanho02 & - & - & $\begin{array}{c}8,088^{* * *} \\
(1,758)\end{array}$ & $\begin{array}{c}8.967^{* * *} \\
(1,443)\end{array}$ \\
\hline Densidade02 & - & - & $\begin{array}{c}-0,011^{* *} \\
(0,005)\end{array}$ & $\begin{array}{c}-0,007^{* *} \\
(0,003)\end{array}$ \\
\hline Constante & $\begin{array}{c}8,871 \\
(42,349) \\
\end{array}$ & $\begin{array}{c}-16,046 \\
(14,954) \\
\end{array}$ & $\begin{array}{c}9,611 \\
(10,256) \\
\end{array}$ & $\begin{array}{c}2,461 \\
(8,218) \\
\end{array}$ \\
\hline $\begin{array}{c}\text { R Quadrado } \\
\text { ajustado }\end{array}$ & 0,767 & 0,544 & 0,836 & 0,845 \\
\hline Erro padrão & 3,827 & 2,031 & 1,992 & 1,632 \\
\hline N. Obs. & 20 & 20 & 20 & 20 \\
\hline
\end{tabular}

${ }^{*} p<0.1{ }^{* *} p<0.05^{* * *} p<0.01$ Erros-padrão robustos em parênteses abaixo de cada coeficiente

Fonte: Produzido pelo autor.

Variáveis nas regressóes

- dind: indicador regional dind para o ano de 2001

- associação: relação entre organização regional e população regional em 2001

- educação: proporção regional de indivíduos com um diploma em 2001

- In asset: investimento coletivo regional per capita no mercado de ações em 2001 (em logaritmo natural)

- In asset02: investimento coletivo regional per capita no mercado de ações em 2002 (em logaritmo natural)

- tamanho02: média do número de membros famílias em nível regional em 
- tamanho03 média do número de membros famílias em nível regional em 2003

- densidade02 densidade populacional regional em 2002 (habitantes $/ \mathrm{km}^{2}$ )

- densidade03 densidade populacional regional em 2003 (habitantes $/ \mathrm{km}^{2}$ )

A Tabela 4 mostra os resultados das nossas regressões. O indicador de capital social dind é negativa e significantemente associado com todas as variáveis de pobreza. Um maior nível de capital social reduz diversas medidas diferentes de pobreza. $\mathrm{O}$ índice afeta negativamente a incidência de pobreza geral e, mais importante, ele afeta o indicador de hiato de pobreza. Evidências empíricas mostram que um aumento de $10 \%$ no indicador de capital social implica em uma diminuição de $15 \%$ do indicador HC. Nas bases do indicador PG, famílias com conexôes diversificadas são mais capazes de escapar da pobreza. Em outras palavras, regióes com um nível mais elevado de capital social apresenta, em média, uma intensidade menor de pobreza. Observe que, ao contrário do índice headcount, a medida do hiato de pobreza mostra quão profunda é a pobreza na região. Em nosso caso, um aumento de $10 \%$ do dind reduz o hiato de pobreza em $7,4 \%$. Isso significa que a distância entre a linha de pobreza relativa $z$ e a média de despesas de una família pobre é reduzida por 7,4\%. Esse relacionamento entre PG e capital social confirma o mecanismo de transição de pobreza descrito na seção 2. O índice dind é uma combinação de laços de encapsulamento e de ponte. Isso pode habilitar as famílias a estenderem seus recursos sociais e escapar da armadilha de aproximaçâo. Assim, quanto maior a média do nível de capital social na região, menor é a proporção de famílias classificadas como pobres, e menor é a distância entre a média de gastos de famílias pobres e a linha da pobreza. Essas razões são bastante evidentes em relação com as variáveis SP e JP. Um aumento de $10 \%$ do indicador de capital social reduz a proporção de famílias "surely poor" e "just poor" por $6,9 \%$ e 6,5\%, respectivamente. Em regióes onde conexóes diversificadas são mais comuns, a porcentagem de famílias extremamente pobres é menor. Atividade associativa apresenta os mesmos comovimentos do nosso índice de capital social, mesmo que isso seja significante apenas em relação ao índice headcount. Maior vida associativa pode ampliar ou aprofundar o senso cívico de engajamento e aumentar a habilidade das pessoas em cooperar umas com as outras. Isso pode ter uma influência positiva na proporção de famílias pobres dentro da área. Diferente dos indicadores de capital social, o nível de educação que consideramos não é significantemente correlacionado com as variáveis de pobreza. Podem existir diversas razões possíveis para esse resultado em particular. A variável potencial de "anos de estudo" têm se mostrado fraca, e até imprecisa, em trabalhos anteriores também 
(FELICE, 2005; COCCIA e PANNUZI, 1996; HELLIWELL, 2002). De acordo com Coccia et al. (1995), a tendência da pobreza dos anos 1980-1995 cresceu independentemente do nível educacional do chefe de família. Felice (2005), em análise de disparidades regionais na Itália do século XIX até o presente, ressalta que tal variável de capital humano sofre de um problema importante. Não levando em conta a mobilidade inter-regional dos estudantes, a qual, de acordo com Felice (2005), tem aumentado notavelmente durante os últimos 20 anos; em especial das regiões do sul para as do norte. $\mathrm{O}$ resultado imediato é que a educação parece ser espalhada uniformemente pelo país. Claro, nas regiōes do norte existem mais pessoas com um diploma, mas também muito mais residentes que nas regiôes sulinas. $\mathrm{Na}$ nossa análise, o tamanho da família é significante e positivamente correlacionado com as medidas de pobreza como a curva de Engel prevê. A riqueza financeira da família é negativamente relacionada às variáveis de pobreza e se torna significante, especialmente quando consideramos as variáveis SP e JP. Em outras palavras, quando consideramos níveis mais específicos de pobreza, a riqueza financeira das famílias desempenha um papel importante. Podemos inferir que as famílias que detêm títulos são menos afetadas negativamente por choques de renda e volatilidade de renda.

\section{Capital social e exclusão social}

Diferente da pobreza, que reflete nas restrições econômicas que as famílias enfrentam, a exclusão social se refere mais as suas dificuldades em acessar recursos. Esses recursos são de vários tipos, como humano (acesso a educação), social (acesso a melhor moradia) e econômico (acesso ao mercado de trabalho e comida, por exemplo). À primeira vista, relacionar exclusão social a capital social pode parecer um exercício tautológico. No entanto, argumentamos que essa relação está longe de ser composta por dois conceitos idênticos. A definição de capital social é empregada neste artigo é completamente operacional e segue a abordagem de Putnam. De acordo com o que introduzimos no começo do artigo, consideramos capital social como o capital de conexôes que surge entre indivíduos. Uma das chaves das suposições em nossa análise é que a combinação entre as ligações de encapsulamento e de ponte, que ocorrem entre indivíduos, representa um importante recurso de bemestar da sociedade. $\mathrm{Na}$ verdade, esse sistema de conexóes por um lado deve facilitar melhor acesso à informação; e por outro lado deve fomentar um senso de reciprocidade e confiança dentro da sociedade. Indivíduos, consequentemente, tendem a cooperar e acreditar mais uns nos outros em sociedades onde o nível de capital social é maior. Exclusão social, em vez disso, se refere a uma série de desconfortos que indivíduos e famílias enfrentam regularmente. Recordando Stranges 
(2007), exclusão social se refere a um processo de empobrecimento por uma acumulação e interação de fatores de risco social. Exclusão social combina fatores como desemprego, baixa escolaridade, saúde e insegurança alimentar. Queremos testar se essas condiçôes são afetadas pelo nível de capital social. Crucialmente, elas não correspondem a essa definição. Em outras palavras, essa seção investigará se um mecanismo de conexóes diversificadas, com reciprocidade, cooperação e confiança entre indivíduos de uma sociedade, pode facilitar melhor acesso a recursos multidimensionais para famílias e melhorar padrôes de vida.

\section{Medidas de exclusão social: Dados e metodologia}

Consideramos duas medidas sintéticas de exclusão social: uma seguida por Stranges (2007) e outra por Capacci e Castagnaro (2003). Uma das limitaçóes de índices sintéticos, reconhecido por Stranges (2007) é sua incapacidade de distinguir os efeitos de cada um dos componentes individuais do índice. Porém, como Stranges (2007) salienta, esses indicadores têm pelo menos duas características atraentes. Primeiramente, eles variam de 0 a 1 , o que significa ser possível posicionar regiôes ou países de acordo com eles. Em segundo lugar, eles são fáceis de entender, o que indica ser possível fazer comparaçôes entre indicadores diferentes e entre indicadores diferentes e regióes e/ou países diferentes. Em terceiro lugar, em nosso caso é muito útil, já que foram construídos em um nível regional.

A medida proposta por Stranges (2007) combina três dimensões principais. Primeiramente, o desconforto econômico baseado na taxa de desemprego. Em segundo lugar, o desconforto social medido com a proporção de famílias enfrentando problemas de moradia (problemas físicos, como eletricidade, vazamentos etc.) e enfrentando dificuldades em comprar bens necessários. Em terceiro lugar, desconforto humano baseado na falta de educação (porcentagem de indivíduos com o diploma de ensino fundamental como o nível mais alto de educação). A metodologia aplicada para construir esse índice segue a usada pelas Nações Unidas na construção do Índice de Desenvolvimento Humano (IDH) e no Índice de Pobreza Humana (IPH).

O índice de exclusão social é uma simples média aritmética de três dimensões (econômica, social e humana) através da seguinte fórmula (equação 5) (para uma explicação mais precisa da metodologia utilizada, veja o Apêndice).

$$
I S E_{i}=\sum_{j=1}^{n} \frac{I_{j i}}{n}
$$


Onde $I$ é o indicador de desconforto, $j=1 \ldots n$ e $n=3$ é o número de dimensóes levadas em conta. Finalmente, $i=1 \ldots s$ onde $s=20$ é o número de regiôes consideradas (Piemonte, Valle d'Aosta, Lombardia... Sardenha).

A segunda medida de exclusão social que consideramos é seguida por Capacci e Castagnaro (2003). A principal diferença entre essa e a anterior é a escolha das dimensóes. Diferente de Stranges (2007), Capacci e Castagnaro (2003) consideram cinco dimensões: desemprego, falta de educação, alta incidência de despesas com alimentação em relação ao total de despesas, má percepção do estado de saúde e famílias que declaram problemas de moradia.

Ambos os índices variam de 0 a 1 . Uma região com um valor $I S E$ perto de 1 sofre de um alto nível de exclusão social, enquanto uma região com um ISE muito baixo tem um padrão de vida geral alto.

A Tabela 5 mostra as principais diferenças estatísticas entre os dois indicadores.

Tabela 5 - Estatísticas de ISE Strange e Capacci-Castagnaro

\begin{tabular}{c|c|c}
\hline & Stranges & Capacci-Castagnaro \\
\hline Média & 0,459 & 0,481 \\
\hline Mediana & 0,376 & 0,447 \\
\hline Desvio Padráo & 0,223 & 0,228 \\
\hline Máxima & 0,712 & 0,833 \\
\hline Mínima & 0,889 & 0,920 \\
\hline Variaçáo & 0,177 & 0,087 \\
\hline N. Obs. & 20 & 20 \\
\hline
\end{tabular}

Fonte: Produzido pelo autor.

O indicador de Strange mostra média, mediana e variação mais baixas que o indicador de Capacci e Castagnaro, embora o desvio padrão não difira muito entre eles. Dependendo de qual índice consideramos, as regióes mudam de lugar quando posicionadas de uma exclusão social alta para uma baixa. No entanto, Stranges (2007) salienta que quando uma amostra é dividida entre essas regiōes tendo um valor de ISE maior que 0.5 (para Stranges esse intervalo identifica regióes de alta exclusão social) e menor que 0.5 (regiôes de baixa exclusão social) não ocorre nenhuma diferença significante no posicionamento.

A Tabela 6 mostra a matriz de correlação entre a pobreza e os indicadores de capital social. 
Tabela 6 - Capital social, ISE e pobreza

\begin{tabular}{c|c|c|c|c|c|c}
\hline & Stranges & $\begin{array}{c}\text { Cap- } \\
\text { Cast }\end{array}$ & HC & PG & Dind & Associaçáo \\
\hline Stranges & 1,00 & - & - & - & - & - \\
\hline Cap-Cast & 0,78 & 1,00 & - & - & - & - \\
\hline HC & 0,77 & 0,85 & 1,00 & - & - & - \\
\hline PG & 0,56 & 0,51 & 0,83 & 1,00 & - & - \\
\hline Dind & $-0,61$ & $-0,41$ & $-0,55$ & $-0,50$ & 1,00 & - \\
\hline Associaçáo & $-0,29$ & $-0,58$ & $-0,35$ & $-0,09$ & $-0,07$ & 1,00 \\
\hline
\end{tabular}

Fonte: Produzido pelo autor.

Os indicadores de capital social são correlacionados negativamente com indicadores de exclusão social. Ao mesmo tempo, indicadores de pobreza e indicadores de exclusão social são positivamente correlacionados. Esse último resultado reforça nossa ideia inicial de considerar ambas as medidas como um contínuo de empobrecimento socioeconômico da sociedade. As Figuras 5 e 6, respectivamente, indicam a relação entre o ISE de Stranges e o dind e o ISE de Capacci-Castagnaro e dind usando uma análise bivariada. Ambos os gráficos mostram claramente uma relação negativa entre exclusão social e capital social. Em ambos os cenários, as regiôes com maior exclusão social e menor capital social pertencem ao sul (Sicília, Sardenha, Campânia, Calábria e Basilicata).

Figura 5 - Capacci-Castagnaro ISE e dind

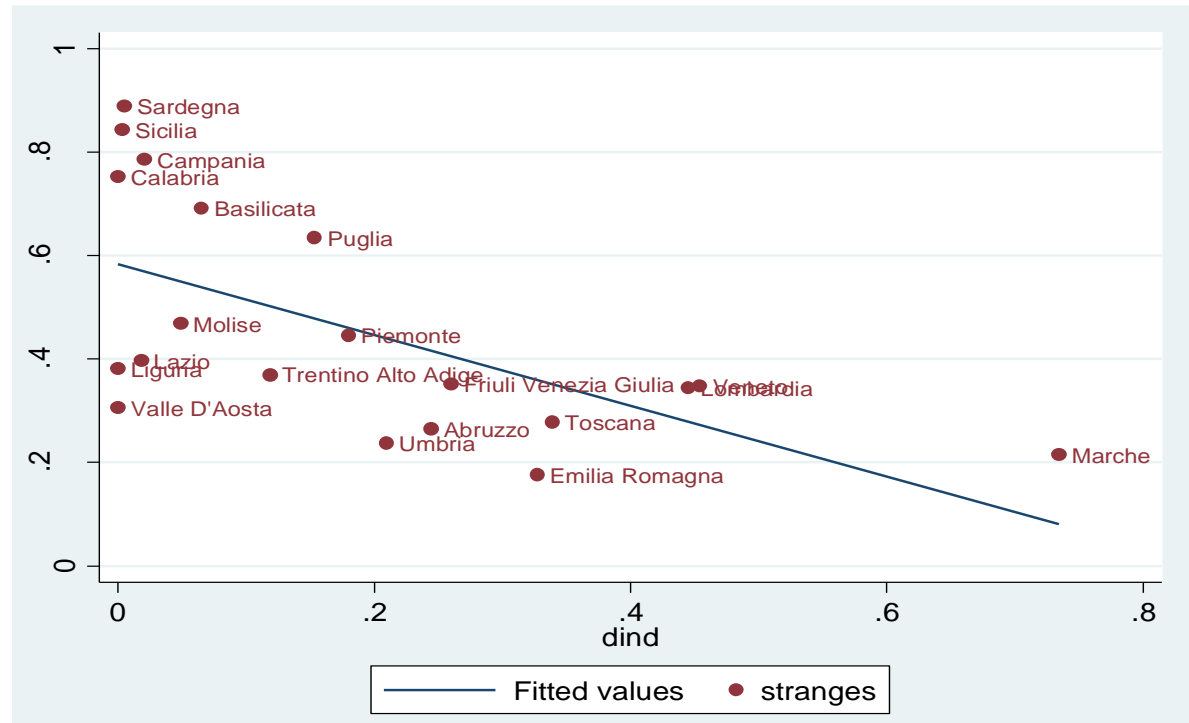

Fonte: Produzido pelo autor. 
Figura 6 - Capacci-Castagnaro ISE e dind

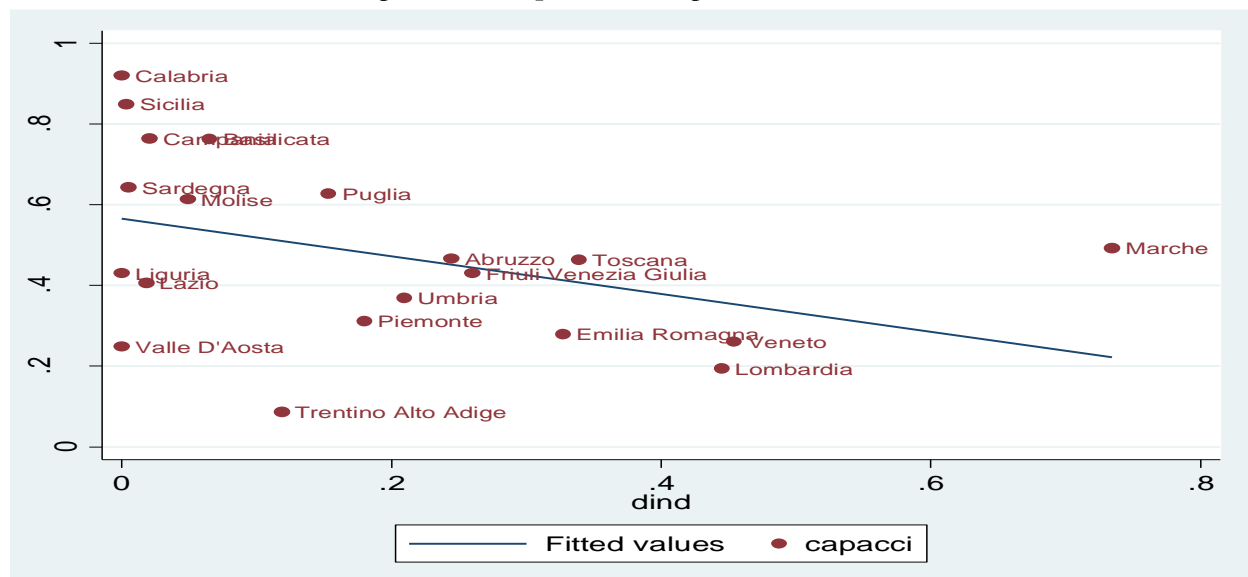

Fonte: Produzido pelo autor.

\section{Análise empírica}

A partir do conceito de capital social, inferimos que na ausência da interação social, um senso de pertencimento a uma comunidade, e engajamento cívico, o nível de exclusão na sociedade pode aumentar. No entanto, o oposto também pode ser aplicado. Uma sociedade na qual os desconfortos econômicos, sociais e humanos são riscos profundos persistentes, vê uma possibilidade reduzida da construção de capital social em suas diferentes dimensões. Para deixar nossa análise mais robusta, configuramos nosso modelo utilizando variáveis de capital social e de exclusão social de anos diferentes. Mais precisamente, nossas variáveis de capital social ("dind" e atividade associativa) são baseadas no ano de 2001, enquanto as variáveis de exclusão social se referem ao período de 2003.

A Equação (6) mostra o modelo empírico que estimamos.

$$
\text { ISE } E_{i}^{m}=\alpha_{0}+\alpha_{1} S c_{i}^{k}+\alpha_{2} \text { logasset }_{i}+\alpha_{3}{\text { logasset } 02_{i}}_{i}+\alpha_{4} X_{i}+u_{i}
$$

$I S E_{\tilde{i}}^{m}$ indicamos a medida de exclusão social $m$ th ( $m=$ Stranges,CapacciCastagnaro) para regiôes $i$ th.

A Equação (6) é uma modificação da equação (4). A principal diferença é a omissão da educação e da densidade populacional. Tal decisão foi feita com o objetivo de minimizar problemas de endogeneidade que essas variáveis possam causar. Em primeiro lugar, ambos os índices ISE incluem o nível de educação. Em segundo lugar, descobrimos que a densidade não é significante em nenhuma dessas 
duas regressões e o coeficiente é bem próximo à zero. Incluindo essas variáveis ou não, não muda o nível de adequação das regressóes ou do comportamento de outras variáveis. A fim de analisar esse mecanismo mais precisamente, como um conceito extremamente teórico, exclusão social implica polarização social: ser parte da sociedade ou não, Bohnke (2001). Em uma abordagem mais operacional, o ISE considera esse "não pertencimento social" como desvantagens econômico-sociais e humanas acumuladas. É provável que nesse índice composto o risco de dimensões diferentes compensem-se ao fazer com que o índice seja menos sensitivo a algumas características geográficas.

Tabela 7 - Capital social, ISE e pobreza

\begin{tabular}{|c|c|c|c|c|}
\hline & $\begin{array}{c}\text { Eq.1 } \\
\text { Stranges }\end{array}$ & $\begin{array}{c}\text { Eq.2 } \\
\text { Capacci } \\
\text { Castagn. }\end{array}$ & $\begin{array}{c}\text { Eq.3 } \\
\text { HC }\end{array}$ & $\begin{array}{l}\text { Eq.4 } \\
\text { PG }\end{array}$ \\
\hline Dind & $\begin{array}{c}-0,505^{* * *} \\
(0,123)\end{array}$ & $\begin{array}{l}-0,146 \\
(0,146)\end{array}$ & $\begin{array}{c}-15.244^{* * *} \\
(3,931)\end{array}$ & $\begin{array}{c}-7.48^{* * *} \\
(1,949)\end{array}$ \\
\hline Associação & $\begin{array}{l}-0,035 \\
(0,061)\end{array}$ & $\begin{array}{c}-0.264^{* * *} \\
(0,042)\end{array}$ & $\begin{array}{c}-5,780^{* *} \\
(2,190)\end{array}$ & $\begin{array}{l}-0,529 \\
(1,287)\end{array}$ \\
\hline Lnasset & $\begin{array}{c}0,018 \\
(0,051) \\
\end{array}$ & $\begin{array}{c}-0,090 \\
(0,064) \\
\end{array}$ & $\begin{array}{l}-1,991 \\
(2,648) \\
\end{array}$ & $\begin{array}{c}1,299 \\
(0,801)\end{array}$ \\
\hline Lnasset02 & $\begin{array}{c}-0,092^{* * *} \\
(0,024)\end{array}$ & $\begin{array}{l}-0,068^{*} \\
(0,036)\end{array}$ & - & - \\
\hline Tamanho03 & $\begin{array}{l}0,387^{*} \\
(0,198) \\
\end{array}$ & $\begin{array}{c}0,062 \\
(0,175) \\
\end{array}$ & $\begin{array}{l}14,740^{*} \\
(7,745) \\
\end{array}$ & $\begin{array}{c}12.224^{* * *} \\
(3,202) \\
\end{array}$ \\
\hline Educação & - & - & $\begin{array}{l}-0,283 \\
(0,330) \\
\end{array}$ & $\begin{array}{l}-0,072 \\
(0,145) \\
\end{array}$ \\
\hline Densidade03 & - & - & $\begin{array}{l}-0,009 \\
(0,011) \\
\end{array}$ & $\begin{array}{c}-0,011^{* *} \\
(0,004)\end{array}$ \\
\hline Constante & $\begin{array}{c}0,283 \\
(1,093) \\
\end{array}$ & $\begin{array}{l}1,909^{* *} \\
(0,885) \\
\end{array}$ & $\begin{array}{c}8,871 \\
(42,349) \\
\end{array}$ & $\begin{array}{l}-16,046 \\
(14,954) \\
\end{array}$ \\
\hline $\begin{array}{c}\text { R Quadrado } \\
\text { ajustado }\end{array}$ & 0,642 & 0,746 & 0,767 & 0,544 \\
\hline Erro padráo & 1,134 & 1,115 & 3,827 & 2,031 \\
\hline N. Obs. & 20 & 20 & 20 & 20 \\
\hline
\end{tabular}

${ }^{*} p<0.1{ }^{* *} p<0.05{ }^{* * *} p<0.01$ Erros-padrão robustos em parênteses abaixo de cada coeficiente

Fonte: Produzido pelo autor.

A Tabela 7 mostra o resultado das regressóes relacionadas à exclusão social e recorda aqueles relacionados à incidência de pobreza e hiato de pobreza. $\mathrm{O}$ índice de capital social dind é negativa e significantemente relacionado ao ISE de Stranges, enquanto ele ainda é negativamente, mas não significantemente relativo ao do 
Capacci e Castagnaro. Conforme o indicador de capital social aumenta por 10\%, o indicador de exclusão social diminui por 5\%. Por outro lado, a atividade associativa é significantemente relativa ao ISE de Capacci e Castagnaro e negativo, mas não significante, ao índice seguido por Stranges. A evidência empírica mostra que, se a proporção de indivíduos envolvidos em atividades associativas aumenta em 10\%, o de exclusão social de Capacci e Castagnaro diminui em 2,6\%. Podem existir diversas razões possíveis para esse resultado em particular. A maioria deles é plausivelmente relacionada à composição das medidas de exclusão social e a escolha das medidas de capital social em vez dos dois conceitos por eles mesmos. Diferente de Stranges (2007), Capacci e Castagnaro (2003) incluem insegurança alimentar e insegurança de saúde no índice composto. Organizaçôes voluntárias podem focar parte de suas atividades ao aliviar esses problemas. Um sistema de rede de contatos informal descrita pelo dind pode não capturar esses problemas e isso pode focar muito mais em desemprego e problemas econômicos (Capítulo 5). Um motivo alternativo pode estar relacionado à natureza dos índices sintéticos. Como mencionado anteriormente, um índice sintético não indica quais dos seus componentes dominam. Isso é suscetível de afetar os resultados de regressóes, se não o sinal de coeficientes, seus níveis de significância. Mantendo essa última explicação como um motivo possível, podemos inferir que as dimensóes de capital social que empregamos condicione o nível de exclusão social através das regióes italianas. A Tabela 7 mostra resultados similares com respeito a medidas de pobreza. Como com a pobreza, o tamanho da família é positivamente relacionado à exclusão social e em caso do ISE de Stranges também é significante. Os recursos financeiros defasados por um ano parecem ambos ser negativa e significantemente relacionados a medidas de exclusão social. Recursos econômicos podem ajudar no caso de problemas de moradia ou períodos de doença.

\section{Conclusões}

O relacionamento entre pobreza e exclusão social é ainda um assunto de análise e discussão entre estudiosos. Eles são os mesmos lados da moeda? A pobreza é uma categoria menor de um conceito mais amplo de exclusão social (BOHNKE, 2001)? O objetivo desse artigo não é tentar resolver esse dilema, em vez disso, investigar se o capital social pode reduzir o empobrecimento socioeconômico da sociedade. Portanto, consideramos pobreza e exclusão social como um contínuo em um processo de degradação socioeconômica. A evidência empírica apresentada nesse artigo mostra que capital social afeta negativamente tanto pobreza quanto exclusão social. Regiôes com maiores níveis de capital social apresentam níveis menores de degradação socioeconômica. A primeira parte da análise dá uma voz empírica ao 
mecanismo de transição da pobreza defendida por Woolcock e Narayan (2000). Descobrimos que um sistema de rede de contatos mais diversificado e um senso de reciprocidade mais elevado reduzem a incidência e intensidade de pobreza. $\mathrm{Na}$ segunda parte do artigo, mostramos que o capital social afeta negativamente a exclusão social. Ambas as medidas de capital são negativamente correlacionadas com medidas de exclusão social. Enquanto nosso índice (dind) se torna significantemente relativo a medidas utilizadas por Stranges (2007), a medida de Putnam de atividade associativa é significante relativa ao ISE, calculado por Capacci e Castagnaro.

Luca Andriani é Professor Assistente da School of Business Economics and Informatics, Birkbeck University of London. E-mail: luca.andriani@bbk.ac.uk.

Dimitrios Karyampas é Professor da University of Reading. Email: karyampas@gmail.com.

\section{Referências}

ANDRIANI Luca; KARYAMPAS, Dimitrios. A New Proxy of Social Capital and the Economic.

Performance across the Italian Regions. Birkbeck. 2008

ATKINSON, Anthony B. The Economies of Inequality Oxford: Clarendon Press. 1983

BANCO DA ITÁLIA. Sintesi delle note sull'andamento dell'economia nelle regioni italiane nel 2003. 2004. Disponível em: <www.bancaditalia.it> Acesso em: XXX

BANCO DA ITÁLIA. Sintesi delle note sull'andamento dell'economia nelle regioni italiane nel 2002. 2003. Disponível em: <www.bancaditalia.it> Acesso em: XXX

BANCO MUNDIAL. World Development Report 2006. Equity and Development. Overview. The World Bank Washington, D.C. 2006. Disponível em: <www.worldbank.org> Acesso em: XXXX BANCO MUNDIAL. Introduction to Poverty Analysis. Poverty Manual, All, JH Revision of August 8. 2005 Disponível em: <www.worldbank.org> Acesso em: XXXX

BOHNKE, Petra. Nothing Left to Lose? Poverty and Social Exclusion in Comparison Empirical

Evidence on Germany. WZB discussion paper, FS III 01-402. Berlim. 2001.

BURCHARDT, Tania. LE GRAND, Julian. PIACHAUD, David. Social Exclusion in Britain. Social Policy and Administration, v. 33, n. 3, p. 227-244, set. 1999.

CAPACCI, Giorgia; CASTAGNARO, Cinzia. L'esclusione social e il prodotto interno lordo: analisi e confronti in Europa paper presented at "Giornate di Studio sulla Popolazione", Universita' di Bari, Bari, 27-29 January. 2003.

COCCIA, Giuliana; PANNUZI, Nicoletta. Poverty in Italy 1980-1995. Inquiry Commission on Poverty. Presidency of the Council of Ministers Department of Information and Publishing. 1996. 
DRIFFILL, John. Growth and Finance. The Manchester School, v. 71, n.4, p. 63-380. 2003

FELICE, Emanuele. Income and Human Development: Measuring regional Disparities In Italy"

Centre for Economic Policy research (CEPR) Conference paper European Growth and Integration since the Mid-Nineteenth Century. 2005.

FERRONI, Marco; MATEO, Mercedes; PAYNE, Mark. Development under Conditions of Inequality and Distrust. Social Cohesion in Latin America. IFPRI Discussion Paper N. 00777. 2008

FUKUYAMA, Francis. Social Capital and the Global Economy. Social Capital: the New Golden

Goose: Faculty of Social and Political Sciences, Cambridge University. 1995.

GABBERT, Silke; WEIKARD, Hans-Peter. The link between Poverty and Undernourishment, Uncovering a Methodological Flaw. Review of Agricultural Economics, v. 27, n.1, p. 150-155. 2005.

GERTLER, Paul; LEVINE, David. MORETTI, Enrico. Do Microfinance Programs Help Families Insure Consumption against Illness? CIDER working paper, 03-129. 2003.

GERTLER, Paul; LEVINE, David. MORETTI, Enrico. Is Social Capital the Capital of the Poor? The Role of Family and Community in Helping Insure Living Standards against Health Shocks. CESifo Economic Stidies, v.52, n. 3, p. 455-499. 2006.

GRANOVETTER, Mark. The Strength of Weak Ties. American Journal of Sociology, n. 78, n. 6, p. 1369-1380, maio 1973.

GRANOVETTER, Mark. Economic Action and Social Structure: the Problem of Embeddedness. American Journal of Sociology, n. 91, n. 3, p. 481-510, nov. 1985.

GROOTAERT, Christiaan. Does Social Capital Help the Poor? A Synthesis of Findings from the Local Level Institutions Studies in Bolivia, Burkina Faso, and Indonesia. The World Bank, Social Development Department. 2001.

GUISO, Luigi; SAPIENZA, Paola; ZINGALES, Luigi. The Role of Social Capital in Financial Development. American Economic Review, v. 94, n. 3, p. 526-556, jun. 2004.

HELLIWELL, John. How's life? Combining individual and national variables to explain subjective well-being. NBER working paper series. National Bureau of Economic Research. Working Paper 9065. julho.2002

HIRSCHL, Thomas. RANK, Mark. The Effect of Population Density on Welfare Participation. Social Force, v. 70, n. 1, p. 225-235. Set, 1991.

ISHAM, Jonathan. The Effect of Social Capital on Technology Adoption: Evidence from Rural Tanzania. In: Conference Opportunities in Africa: Micro-evidence on Firms and Households. The Centre for The Studies of African Economies, 9-10 abril. 2000.

ISTAT, Istituto Nazionale di Statistica. "La poverta' e l'esclusione sociale nelle regioni italiane. Anno 2002”. Dezembro, 2003. Disponível em: <www.istat.it> . Acesso em: XXX.

ISTAT, Istituto Nazionale di Statistica. 8th General Census on Industry and Industrial Districts. 2001. Disponível em: <www.istat.it> . Acesso em: XXX.

ISTAT, Istituto Nazionale di Statistica. Voluntary Organizations in Italy. 2001. Disponível em: $<$ www.istat.it> . Acesso em: XXX.

KNACK, Stephen. KEEFER, Philip. Does Social Capital Have an Economic Payoff? A Cross-Country Investigation. Quarterly Journal of Economics, v. 112, n.4, p. 1251-1288. 1997

LIN, Nan. Social Capital a theory of Social structure and Action. Cambridge: Cambridge University Press, 2001.

NARAYAN, Deepa; PRITCHETT, Lant. Cents and Sociability. Household Income and Social capital in Rural Tanzania. Policy Research Working Paper. World Bank, julho. 1997. 
NARAYAN, Deepa. WOOLCOCK, Michael. Social Capital: Implications for Development Theory, research and Policy. The World Bank Research Observer, v. 15, n. 2, p. 225-249, agosto. 2000.

NEGRI, Nicola. I concetti di poverta' ed esclusion sociale” Polis, XI, 1, abril.1995

OSTROM, Elinor. Beyind Markets and States: Polycentric Governance of Complex Economic Systems. American Economic Review,v. 100, n.3, p. 641-672. 2010.

Oxendine, Alina. Inequality and Isolation: Lessons from a Multi-Level Analysis. In: Annual Meeting of the International Society of Political Psychology, Portland, julho. 2007.

PALDAM, Martin. Social Capital: One or Many? Definition and Measurement. Journal of Economic Surveys, v. 14, n. 5, dez. 2000.

PISTAFERRI, Luigi. Informal Networks in the Italian labour Market. Giornale degli Economisti, v. 58, n.3-4, p. 355-375. 1999.

PUTNAM, Robert. Bowling Alone: the collapse and revival of American community. New York: Simon \& Schuster, 2000.

PUTNAM et al.. Making Democracy Work. Princeton: Princeton University Press, 1993

SABATINI, Fabio. Social Capital and Social Network: A new Framework for Measurement.

University of Rome, Working Paper, n. 83, 2005a.

SABATINI, Fabio. The Role of Social Capital in Economic Development. Investigating the Causal Nexus through Structural Equations Models. EconWPA, 2005b.

SABATINI, Fabio. The Empiric Social Capital and Economic Development: A Critical Perspective. Fondazione ENI Enrico Mattei Nota di Lavoro, v. 15. 2006

SAXENIAN, AnnaLee. Regional Advantage Culture and Competition in Silicon Valley and Route 128. Harvard: Harvard University Press, 1996

SEN, Amartya. On economic inequality. Oxford: Clarendon Press, 1997.

STRANGES, Manuela. Social Exclusion in the Italian Regions: A Synthetic Approach of Measurement. In: Quetelet Seminar 2007 - Poverty Dynamics and Vulnerability. Measures and Explanations in Demography and Social Sciences, Universite Catholique de Louvaine, Bélgica, November 27-30. 2007.

TOWNSEND, Peter. Poverty in the United Kingdom. Harmondsworth, Penguin. 1979.

VAN BASTELAER, Thierry. Does Social Capital Facilitate the Poor's Access to Credit? A Review of the Microeconomic Literature. Social Capital initiative, Working Paper, n.8. World Bank February. 2000 .

WOOLCOCK, Michael. Social Capital and Economic Development: toward a theoretical synthesis and policy framework. Theory and Society, v. 27, n. 2, p. 151-208, 1998.

WOOLCOCK, Michael. The Place of Social Capital in Understanding Social and Economic Outcomes. Canadian Journal of Policy Research, v. 2, n. 1, p. 11-17, fev. 2001. 


\section{Apêndice}

\section{Apêndice 1 O indicador de Capital Social DIND}

Como dissemos no artigo, o indicador de capital social que desenvolvemos foi inspirado no chamado instrumento de Putnam. Recordando Putnam, rede de contatos e atividades associativas sáo estruturas importantes onde o capital social pode crescer. Esse tipo de abordagem é conhecido na literatura como Instrumento de Putnam. Analisando a diferença em termos de governança, desempenho institucional e bem-estar entre o Sul e o Norte da Itália (PUTNAM et al., 1993), Putnam et al. consideram a vida associativa como uma das variáveis cruciais (outras variáveis são leitores de jornais, comparecimento eleitoral, padróes de preferência de voto). Em outras palavras, participação em organizaçóes voluntárias e associaçôes sociais promovem entre membros normas coletivas e confiança, as quais são fundamentais para a produçáo e a manutenção do bem-estar da comunidade. Apresentaremos o presente "instrumento" usando a formalização feita por Martin Paldam (2000).

Considere uma região (ou uma área) e, consequentemente, considere uma população Ai pertencente a essa região. A atividade associativa dentro da região é baseada nas organizaçóes voluntárias $(\mathrm{OVs})$ que funcionam localmente. O objetivo é calcular a densidade das OVs e considerá-las como um indicador de capital social. O processo é como se segue:

Considere os seguintes ingredientes:

A $i$ onde $i=1,2, \ldots . ., n$ é a população

$\Pi=$ densidade de Organizaçôes Voluntárias (OVs) a qual é um indicador de CS (Esse é o instrumento de Putnam).

Duas formas de obtenção do índice de Putnam:

1) Ao perguntar às pessoas a quantas organizações eles pertencem

2) Ao perguntar às organizaçóes quantos membros elas têm

1) =2): a pesquisa deve dar o mesmo resultado. Caso exista uma diferença, é possível que isso seja devido a observaçóes faltantes ou outros problemas interessantes.

Primeira forma

$P i=$ uma pessoa pertencente a $y i$ organizaçóes

$N=\sum_{i=1}^{n} y_{i} \quad$ para $i=1,2, \ldots, n$ pessoas

consequentemente

$\Pi=\frac{N}{n}$

Segunda forma

A organização $j$ tem $z j$ membros

$M=\sum_{j=1}^{m} z_{j} \quad$ para $j=1,2, \ldots, m$ organizações 
consequentemente

$$
\Pi=\frac{M}{n}
$$

1) $=2$ ) significa que $\Pi=\frac{N}{n}=\frac{M}{n}$

Observe que em um país homogêneo, $\Pi$ pode não ser provável que varie muito em todo o país.

Ao construir nosso índice, consideramos os Distritos Industriais (DIs) como comunidades particulares e os trabalhadores dentro dos distritos como membros dessa comunidade. A ideia é, portanto, construir um novo índice usando a mesma estrutura e método aplicado no de Putnam.

Como no instrumento de Putnam, consideramos uma população e membros de atividades associativas, no nosso caso DIs em vez de OVs.

Se considerarmos o território italiano, isso é dividido em 20 regióes com seu próprio "governo regional" e administração. Em termos socioeconômicos, cada região é composta pelo que é chamado de sistemas de trabalho local (STL), os quais indicam grupos territoriais de municipalidades (comuni) estatisticamente comparáveis tal como:

Cada agrupamento pode apenas incluir municipalidades vizinhas pertencentes a nenhum outro grupo territorial

Cada agrupamento é independente, no sentido de que residentes em cada área principalmente trabalha para empresas locais, cuja sede está em um dos município que compóem as STL.

Portanto, de acordo com a definição empírica, DIs são STL que atendem determinados critérios de concentração industrial e, em especial, duas condiçóes precisam ser satisfeitas.

Primeiramente, o nível de emprego de empresas pequenas operando no STL especializadas em atividade manufatureira devem ser mais que 50\% do total de emprego na mesma atividade no nível da STL. Em segundo lugar, no caso de ter apenas uma empresa de médio porte no grupo, então o número de trabalhadores nas companhias pequenas têm que ser maior que $50 \%$ do número de trabalhadores na companhia de médio porte (assim tal sistema não estará polarizado).

Seguindo a mesma estrutura do índice de Putnam, considera uma área socioeconomica, por exemplo, uma região. Existe uma população de trabalhadores $j=1$, $2, \ldots, m$ que é a soma de todos os trabalhadores pertencentes ao Sistema de Trabalho Local da região.

Queremos saber quantos trabalhadores na área trabalham para os DIs.

$d j$ distrito industrial tem $l j$ trabalhadores

$$
L=\sum_{j=1}^{m} d_{j}
$$




$$
\text { Portanto } \frac{L}{m}=D I N D
$$

\section{Apêndice 2 A linha de pobreza relativa e as medidas de pobreza}

A linha de pobreza relativa $z$, feita pelo ISTAT se refere ao consumo per capita $c$, ajustada pela padronizaçáo do fator $\beta$, chamado de "a escala de equivalência", utilizada para determinar a linha de pobreza quando o número dos membros familiares for diferente de "2".

Portanto se $c$ é o consumo per capita, então:

$$
z=\beta c
$$

A Tabela (a) mostra os diferentes fatores

A Tabela (D1) Membros da Família e "Escala de Equivalência" (2002)

\begin{tabular}{c|c}
\hline Membros da família & $\beta$ \\
\hline 1 & 0,60 \\
\hline 2 & 1,00 \\
\hline 3 & 1,33 \\
\hline 4 & 1,63 \\
\hline 5 & 1,90 \\
\hline 6 & 2,16 \\
\hline 7 (ou mais) & 2,40 \\
\hline
\end{tabular}

Fonte: "La poverta' e l'esclusione sociale nelle regioni italiane" (ISTAT, 2003)

De acordo com ISTAT (2003), a linha de pobreza relativa em 2002 para uma família de dois membros é

$z=1 * 823,45=€ 823,45$

Enquanto para uma família de quatro membros é

$\mathrm{z}=1,63 * 823,45=€ 1342,22$

onde $€ 823,45$ foi calculado como consumo per capita na Itália em 2002.

Consequentemente, uma família de dois membros é considerada pobre se tem um gasto médio mensal de consumo menor ou igual a média nacional per capita $(€ 823,45)$.

O Índice Headcount (HC) mede a proporção da população que é contada como pobre (BANCO MUNDIAL, 2005). Se PO é nosso índice, então

$$
P_{0}=\frac{1}{N} \sum_{i=1}^{N} I\left(y_{i}<z\right)
$$

Onde

$y_{i}$ é a renda real da família $i$ e $\mathrm{N}$ indica o total de famílias da amostra 
Observe que $I($.$) é uma função indicadora de tal forma que:$

$$
\begin{gathered}
I(\mathrm{O})=1 \text { if } y_{i}<z \\
I(\mathrm{o})=0 \text { de outramaneira }
\end{gathered}
$$

O índice pode ser expresso em uma forma mais simples como na equaçáo abaixo

$$
P_{0}=\frac{N_{p}}{N}
$$

onde $N p$ é o número de pobres e $N$ o total da população.

Por exemplo, se resultar em identificar 20 famílias classificadas como pobres sobre uma amostra de 100 famílias, então a equação (3) será

$$
P_{0}=\frac{20}{100}=0.2=20 \%
$$

Por isso, em nosso cenário hipotético o índice é 0.2 , o que significa que a proporçáa de famílias que são contadas como pobres é de $20 \%$.

O Índice de Hiato de Pobreza indica a intensidade da pobreza. Em palavras simples, ele mede, em média, quão longe os gastos de famílias pobres caem abaixo da linha de pobreza. Podemos formalizar o índice de hiato de pobreza como se segue:

$$
G_{i}=\left(z-y_{i}\right) I\left(y_{i}<z\right) \quad(\mathrm{C} 4)
$$

onde $G_{i}$ é o hiato de pobreza e novamente

$$
\begin{gathered}
I(.)=1 \text { if } y_{i}<z \\
I(.)=0 \text { de outramaneira }
\end{gathered}
$$

Portanto

$$
P_{1}=\frac{1}{N} \sum_{i=1}^{N} \frac{G_{i}}{z}
$$

onde $P_{1}$ é o índice hiato de pobreza.

É importante verificar como a incidência de pobreza varia de acordo com como a pobreza é definida. Para esse propósito, ISTAT definiu dois índices extras de incidência de pobreza: o indice "certamente pobre" (SP) e o indice "somente pobre" (JP).

Os dois índices pode ser formalizados da seguinte forma:

$$
S P \rightarrow \mu<\alpha z \quad \text { (C6) }
$$

onde $\alpha=0.8$, o qual significa que o índice surely poor identifica famílias as quais os gastos são menos que $80 \%$ do padrão da linha de pobreza. $z$

Enquanto

$$
l P \rightarrow z \leq \gamma \leq \alpha z \quad(\mathrm{C} 7)
$$

A expressão (C7) significa que o índice just poor identifica famílias as quais os gastos estáo entre $80 \%$ da linha de pobre $z$ e própria linha padráo de pobreza. 


\section{Apêndice 3 Medidas de exclusäo social}

As medidas de exclusão social são construídas usando a mesma estrutura aplicada pelas ONU para computar o Índice de Desenvolvimento Humano (IDH) (equação C8 abaixo).

$$
I S E_{i}=\sum_{j=1}^{n} \frac{I_{j i}}{n}
$$

Onde $I$ é o indicador de desconforto, $j=1 \ldots n$ e $n=3$ é o número de dimensóes levadas em conta. Finalmente, $i=1 \ldots s$ onde $s=20$ como o número de regióes consideradas (Piemonte, Valle d'Aosta, Lombardia.... Sardenha). O índice de desconforto é (equação C9 abaixo)

$$
I_{j i}=\frac{x_{j i}-\min \left(x_{j}\right)}{\max \left(x_{j j}\right)-\min \left(x_{j}\right)}
$$

Onde o numerador é a diferença entre o valor gravado para cada regiáo em alguns aspectos do desconforto e o valor mínimo do mesmo indicador (a regiáo apresentando o valor mínimo). O denominador é a diferença entre o valor máximo e o valor mínimo de distribuição.

\section{Apêndice 4-Distribuiçāo geográfica da Itália}

Noroeste: Vale d'Aosta (VdA) Piemonte (Pie) Lombardia (Lo), Ligúria (Lg),

Nordeste: Friul-Veneza Júlia (FVG), Trentino-Alto Ádige (Ta), Vêneto (Ve), Emília-Romanha (ER)

Centro: Toscana (To), Marcas (Ma), Úmbria (Um), Lácio (La)

Sul: Abruzos (Ab), Molise (Mo), Campânia (Ca), Apúlia (Pu), Basilicata (Ba), Calábria (Cal), Sicília (Sic), Sardenha (Sa)

Ilhas: Sicília(Sic), Sardenha (Sa) 
112 | Luca Andriani e Dimitrios Karyampas

\section{Apêndice 5-Variáveis}

Tabela com variáveis

\section{Variáveis dependentes}

\begin{tabular}{c|c|c}
\hline$H C$ & $\begin{array}{c}\text { índice de pobreza headcount } \\
\text { regional em 2003 }\end{array}$ & ISTAT \\
\hline$P G$ & $\begin{array}{c}\text { índice de hiato de pobreza } \\
\text { regional em 2003 }\end{array}$ & ISTAT \\
\hline$S P$ & $\begin{array}{c}\text { índice de surely poor regional } \\
\text { em 2002 }\end{array}$ & ISTAT \\
\hline$J P$ & ISTAT \\
\hline Stranges & 2002 $\begin{array}{c}\text { índice regional de exclusáo } \\
\text { social em 2003, computado } \\
\text { por Stranges }\end{array}$ & Stranges (2007) \\
\hline Cap-Cast & $\begin{array}{c}\text { índice regional de exclusão } \\
\text { social em 2003, computado } \\
\text { por Capacci e Castagnaro. } \\
\text { Variáveis dependentes }\end{array}$ & Capacci e Castagnaro (2003) \\
\hline
\end{tabular}

\begin{tabular}{|c|c|c|}
\hline Dind & relação & Andriani e Karyampas (2008) \\
\hline Associação & $\begin{array}{l}\text { relação entre organizaçáo } \\
\text { regional e população regional } \\
\text { em } 2001\end{array}$ & ISTAT \\
\hline Educaçāo & $\begin{array}{c}\text { proporção regional de } \\
\text { indivíduos com um diploma } \\
\text { em } 2001\end{array}$ & ISTAT \\
\hline lnasset & $\begin{array}{l}\text { investimento coletivo regional } \\
\text { per capita no mercado de açóes } \\
\text { em } 2001\end{array}$ & Banco da Itália \\
\hline Inasset02 & $\begin{array}{l}\text { investimento coletivo regional } \\
\text { per capita no mercado de açốes } \\
\text { em } 2002\end{array}$ & Banco da Itália \\
\hline tamanho03 & $\begin{array}{l}\text { média do número de membros } \\
\text { familiares em nível regional em } \\
2003\end{array}$ & ISTAT \\
\hline Tamanho02 & $\begin{array}{l}\text { média do número de membros } \\
\text { familiares em nível regional em } \\
2002\end{array}$ & ISTAT \\
\hline Densidade03 & $\begin{array}{l}\text { densidade populacional } \\
\text { regional em } 2003\end{array}$ & ISTAT \\
\hline
\end{tabular}




\begin{tabular}{l|c|l}
\hline & $\left(\right.$ habitantes $\left./ \mathrm{km}^{2}\right)$ & \\
\hline Densidade02 & $\begin{array}{c}\text { densidade populacional } \\
\text { regional em } 2002 \\
\left(\text { habitantes } / \mathrm{km}^{2}\right)\end{array}$ & ISTAT \\
\hline
\end{tabular}


